\title{
Oral Health Status of the Refugee Population in Utah
}

\author{
Ryan Knighton' ${ }^{1}$, Hanthao Thi Phan ${ }^{1}$, Maria Cala ${ }^{2}$, Gerald Brown ${ }^{3}$, Tejinder P Singh ${ }^{1}$, Mauricio Agramont ${ }^{2}$, \\ Franklin Garcia Godoy ${ }^{4}$, John M Powers ${ }^{5}$ and Lilliam M Pinzon ${ }^{1 *}$
}

${ }^{1}$ University of Utah-School of Dentistry: 530 South Wakara Way, Salt Lake City, USA

${ }^{2}$ Midvale Community Building Community: 49 West Center Street, Midvale, USA

${ }^{3}$ Utah Department of Workforce Services: 5735 S Redwood Rd, Taylorsville, USA

${ }^{4}$ University of Tennessee Health Science Center-College of Dentistry: 875 Union Avenue, Memphis, USA

${ }^{5}$ Dental Consultants, Inc, 3110 W Liberty, Ann Arbor, USA

*Corresponding author: Lilliam M Pinzon, University of Utah-School of Dentistry: 530 South Wakara Way, Salt Lake City, Utah 84108, USA.

Received Date: May 19, 2021

Published Date: June 03, 2021

\begin{abstract}
Introduction: Refugees arriving and living in the United States have been shown to experience high levels of oral health disease and are often in need of extensive treatment. Previous studies have identified high levels of untreated caries, periodontal disease, orofacial disease and disability. Utah.

Objectives: This pilot project aimed to identify current gaps in oral health knowledge, attitudes and treatment needs among refugees living in

Methods: The cross-sectional study was conducted at partner sites identified by the Refugee Education \& Training Center, State of Utah. A convenience sample of 103 adults was recruited from the refugee communities settled in Utah. Data collection included the following elements: demographic characteristics, self-reported oral health status, attitudes, and knowledge, DMFT (decayed, missing, filled teeth), and periodontal status.

Results: Clinical findings revealed pervasive oral health concerns and treatment needs. Only $14 \%$ were evaluated to have healthy periodontal conditions, while $86 \%$ of participants had a least one site of untreated decay. All participants were evaluated to be in need of treatment. Approximately $36 \%$ required prompt treatment, while $43.7 \%$ were evaluated to require urgent treatment due to pain or infection. This study also identified low levels of oral health knowledge, with only $13 \%$ answering all knowledge questions correctly.

Conclusion: This study provided evidence of the extent of oral disease and decay among refugees resettled in Utah and identified the low levels of oral health knowledge in this population. Educational program, especially those evaluate cultural perception, would be a powerful avenue for improving the oral health status of refugees living in Utah.
\end{abstract}

Keywords: Vulnerable population; Socioeconomic factors; Health education; Attitude to health; Epidemiologic methods; Patient health questionnaire; Health status disparities; Health status

\section{Introduction}

A refugee is a person that "owing to a well-founded fear of being persecuted for reasons of race, religion, nationality, membership of a particular social group or political opinion, is outside the country of his or her nationality and is unable to or, owing to such fear, is unwilling to avail himself of the protection of that country"
[1]. Among refugees, one of the most common health problems reported by US organizations after initial screening is oral healthrelated [2]. Previous research reported high levels of untreated caries, periodontal disease, orofacial disease and disabilities among refugees [2-4]. 
It is well known that poor oral health care is often driven by a lack of literacy, low socio-economic status, lack of insurance, lack of transportation, inability to take time off from work or school, habits (smoking, drugs, etc.) and diet [5-7]. In addition to these challenges, refugees also face unique barriers to oral health, including torture related to the oral cavity, differing cultural values, language barriers, lack of access to dental services and/or oral health education at refugee camps, poor diet and hygiene, lack of fluoridated water, bruxism and reflux caused by anxiety and mental health issues [8-12].

Utah is home to a growing number of refugees arriving from various parts of the world bringing a diversity of culture, traditions, skills, and experiences. Utah's resettlement organizations report an average yearly intake of 1,000-1,200 refugees [13]. From January 1 to December 31 of 2015, the Utah Department of Health reported 583 female and 587 male refugees for a total of 1,170 new arrivals in Utah [14]. New arrivals were skewed young, with 451 less than 15 years old, 228 from 15-34 years old, 366 from 25-44 years old, 106 from 45-64 years old, and 19 over 64 years old [14]. When refugees arrive in Utah, they are provided resettlement assistance through Catholic Community Services or the International Rescue Committee. These institutions facilitate programs that support and train refugees to help them integrate to the community and support themselves. These programs include English language learning, trainings and counseling for employment, micro-business trainings (e.g., Business 101, childcare licensing, etc.), computer literacy and IT training [15].

The resettlement agenciesalso provide health services, including dental services for the first three months following their arrival in Utah [16]. Among refugees arriving between 2009 and 2013, 2,312 received oral health care treatment. A total of 21,583 procedures were performed, including oral evaluation, radiographs, coronal polishing, sealants, space maintainer, restorations (amalgam and composites), crown, root canal treatment, periodontal scaling, extractions, biopsy of oral tissue, excision of benign tumor, abscess treatment, and dentures [17].

It should also be noted that the nature of the dental procedures provided to refugee populations upon arrival is often urgent, providing a short-term "band-aid treatment." While the treatment provided in this initial period is crucial to helping this disadvantaged population improve their oral health, broader indicators of untreated caries teeth, periodontal disease, orofacial disease and disabilities, and other needs that extend beyond the initial resettlement period are not systematically reported. Additional research is needed to provide a more comprehensive picture of the oral health needs among this community. This pilot project aimed to identify current gaps in oral health knowledge, attitudes and oral health status among refugees living in Utah. The results provided by this study might allow us to create strategies for designing, planning and implementing programs to reduce the burden of oral and dental diseases among vulnerable refugee populations.

\section{Methods}

\section{Study design and participants}

The cross-sectional study was conducted at partner sites identified by the Refugee Education \& Training Center, State of Utah. A convenience sample of 103 adults was recruited from the refugee communities settled in Utah. The recruitment was enabled by the International Rescue Committee (IRC), Catholic Community Services of Utah (CCS), Refugee and Immigrant Center-Asian Association of Utah (RIC-AAU) and their allied service providers. Ethical clearance was obtained from the Institutional Review Board of the University of Utah (IRB\#00097739). Verbal informed consent was obtained from all participants. The study conforms to STROBE Guidelines.

\section{Measures}

Data collection included measures of caries experience; decayed (D), missing (M), filled (F) teeth, oral hygiene and periodontal status; community periodontal index of treatment needs (CPITN) recommended by the WHO, and self-reported status of oral health, knowledge, and attitude according to the guidelines of the American Dental Association (ADA) and the Health Policy Institute (HPI) $[18,19]$. The examiners and study personnel were trained and calibrated in multiple sessions to minimize interobserver variability. Partner organizations provided information on anticipated cultural competencies in conducting the study.

The clinical oral examination and interviews were conducted at various sites selected by the study collaborators ensuring convenience to the study participants, adequate lighting, minimal noise disturbance, and appropriate privacy. All sessions commenced with the description of the nature of the study, verbally and in print form. If participants were interested in participating, appointments were made for the same day.

The interviews to collect data on demographics, oral health status, knowledge and attitude were conducted for consenting adults only. Services of an interpreter were used wherever necessary. Oral examination was conducted in a separate room with adequate comfortable seating for the examinee and the operator and sufficient light. A non-magnifying dental mouth mirror, explorer and WHO probe without any provision for drying were used to record the DMFT and CPITN scores. DMFT was scored by adding the number of decayed (D), missing (M), filled (F) teeth for every individual. Gingival bleeding and depth of the gingival sulcus were recorded as per the guidelines of the CPITN index. The oral cavity was divided into six sextants (3 each for the maxillary and mandibular arch); first included tooth number 2 to 5 , second, tooth number 6 to 11, third, tooth number 12 to 15 and similarly for the mandibular arch. The following index teeth were used; $2 / 3,8,14 / 15,18 / 19,24$ and 30/31. Periodontal treatment needs were assessed for all individuals.

The following definitions were used: 
TN 0: healthy periodontal conditions with no need for periodontal treatment.

TN 1: gingival bleeding, indicating a need for improving personal oral hygiene of the individual.

TN 2: shallow periodontal pockets ( 4 to $5 \mathrm{~mm}$ ), indicating a need for scaling and improving personal oral hygiene of the individual.

TN 3: deep periodontal pockets ( $6 \mathrm{~mm}$ or more) indicating need for scaling \& root planing and improving the personal oral hygiene of the individual.

Data was collected on assessment forms as per the WHO guidelines.

The collected information was entered by a graduate research assistant into a secure database. All data were cleaned and analyzed using STATA version 14.2 (Stata Corporation, College Station, Texas)

Table 1: Demographic Characteristics.

\section{Results}

\section{Demographic characteristics}

A total of 103 persons aged 18 to 65 years participated in this study. Of these, $65 \%$ were women. A majority of the participants were between the ages of 30 and 49 (54.4\%), with a mean age (SD) of 37.5 (11.6) years (Table 1). The primary countries of origin included Congo (19.4\%), Iraq (18.4\%), and Somalia (18.4\%), with the remaining sample originating in various countries in Africa (20.4\%), Asia (18.4\%), and South America (3.9\%). The country of origin was unknown for one participant (1.0\%, Table 1). Sixty-three percent of the sample had less than a high school-level education. Approximately $32 \%$ were employed full-time, and nearly $80 \%$ reported an annual household income of less than $\$ 15,000$ (Table 1). Forty-seven percent of the participants did not have health insurance.

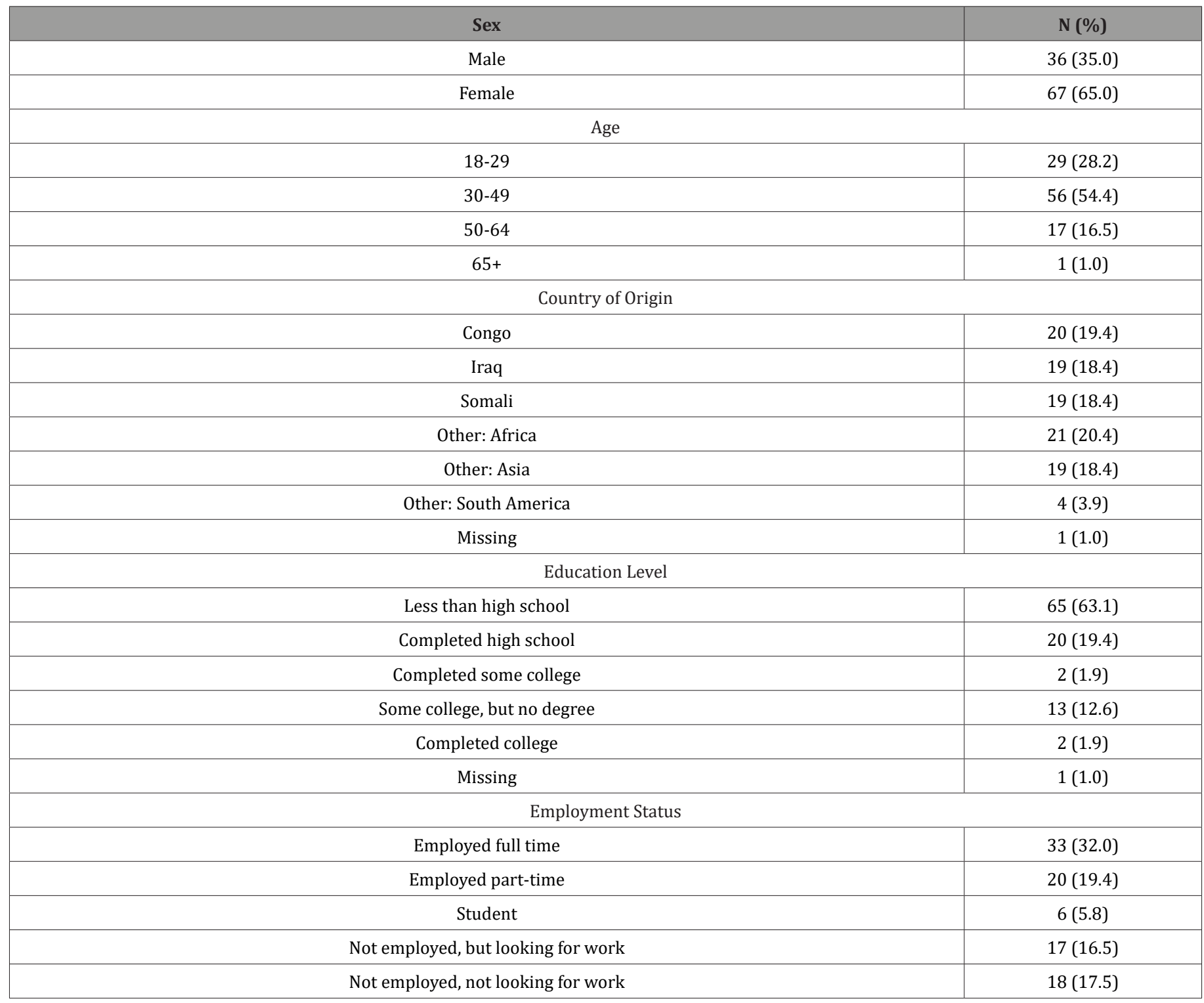




\begin{tabular}{|c|c|}
\hline Not employed, unable to work due to disability or illness & $6(5.8)$ \\
\hline Stay-at-home spouse or partner & $3(2.9)$ \\
\hline \multicolumn{2}{|l|}{ Household Income } \\
\hline Less than $\$ 15,000$ & $82(79.6)$ \\
\hline$\$ 15,000-\$ 24,999$ & $15(14.6)$ \\
\hline$\$ 25,000-\$ 34,999$ & $1(1.0)$ \\
\hline$\$ 35,000-\$ 49,999$ & $2(1.9)$ \\
\hline Missing & $3(2.9)$ \\
\hline \multicolumn{2}{|l|}{ Marital Status } \\
\hline Never married & $20(19.4)$ \\
\hline Married or civil union & $74(71.8)$ \\
\hline Divorced & $2(1.9)$ \\
\hline Separated & $2(1.9)$ \\
\hline Widow/Widower & $4(3.9)$ \\
\hline Living with partner & $1(1.0)$ \\
\hline \multicolumn{2}{|l|}{ Insurance Status } \\
\hline Insured & $43(41.8)$ \\
\hline Uninsured & $48(46.6)$ \\
\hline Don't know & $3(2.9)$ \\
\hline Missing & $9(8.7)$ \\
\hline
\end{tabular}

\section{Oral health behaviors}

Eighty-one percent of the participants reported using toothbrush and toothpaste as hygiene tools. Of those who reported using toothpaste, $23.4 \%$ reported using a fluoride-containing toothpaste, while $52 \%$ did not know if they use toothpaste that

Table 2: Oral Health Behaviors and Service Utilization Patterns.

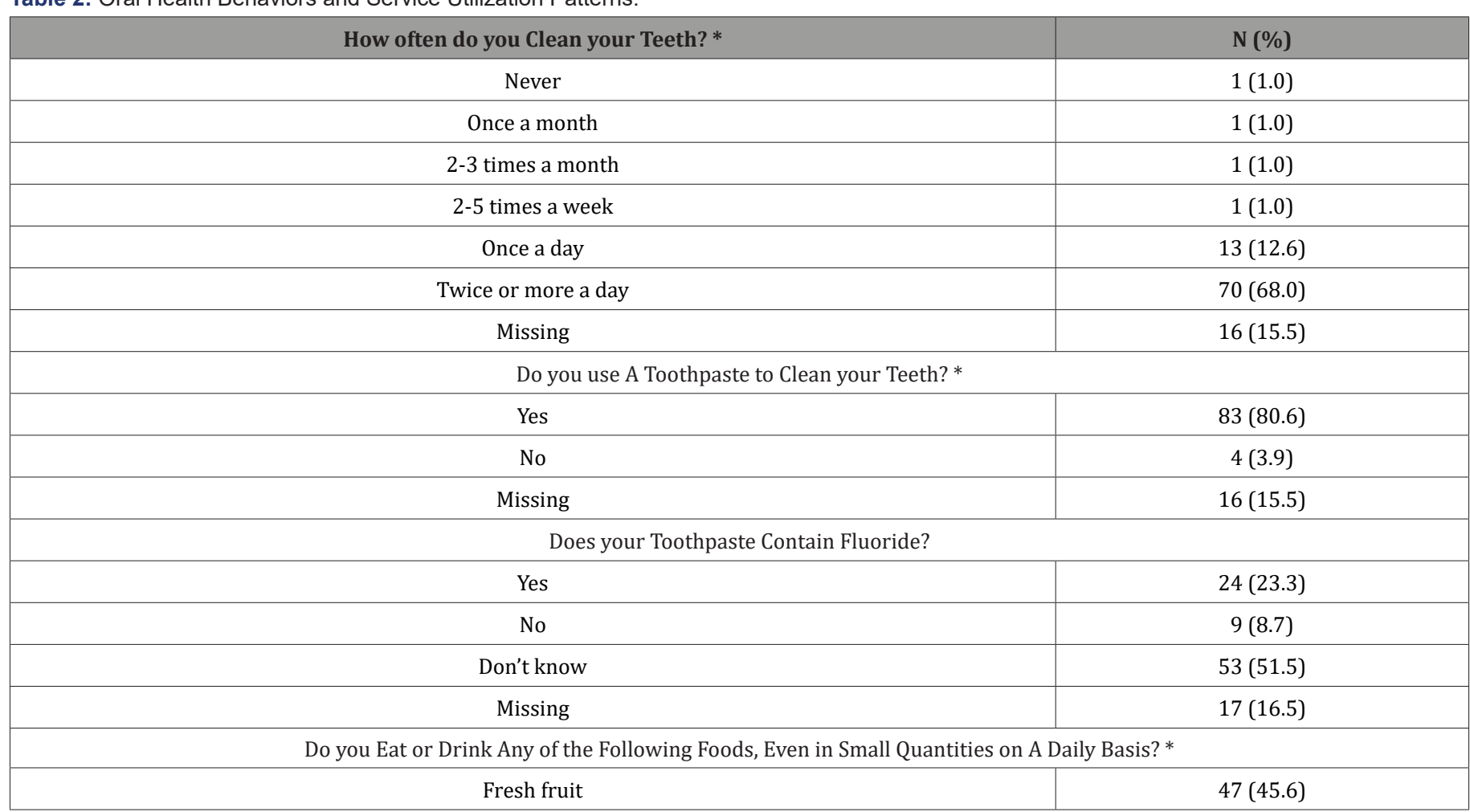

contains fluoride (Table 2). Sixty-eight percent of participants reported cleaning their teeth twice or more a day, while $13 \%$ clean their mouth once a day (Table 2). In reporting daily consumption of sugar-containing food or drink, 46\% reported fresh fruit, $43 \%$ reported coffee/tea with sugar, and $9 \%$ reported lemonade, CocaCola or other soft drinks (Table 2). 


\begin{tabular}{|c|c|}
\hline Biscuits, cakes, cream cakes & $8(7.8)$ \\
\hline Jam or honey & $7(6.8)$ \\
\hline Chewing gum with sugar & $18(17.5)$ \\
\hline Sweets/candy & $7(6.8)$ \\
\hline Lemonade, Coca-Cola, or other soft drinks & $9(8.7)$ \\
\hline Tea/coffee with sugar & $44(42.7)$ \\
\hline
\end{tabular}

*Sixteen subjects were inadvertently not asked these questions. Their responses are considered missing.

\section{Oral health service utilization patterns}

Twenty-nine percent reported never having visited the dentist prior to this research project. Only $24.3 \%$ of participants reported having seen a dentist within the last year (Table 3). For 21\% of respondents, the reason for the last visit to the dentist was pain or trouble with teeth, gums or mouth, while $19 \%$ of participants last saw a dentist for routine check-up/treatment (Table 3). When asked about reasons for not visiting the dentist more frequently, $36 \%$ reported not being able to afford to go to the dentist, with an additional 32\% reported having to pay out of pocket due to many services not being covered by insurance or Medicaid (Table 3).

Table 3: Oral Health Service Utilization Patterns.

\begin{tabular}{|c|c|}
\hline \multicolumn{2}{|l|}{ How long since you last had a dental visit? } \\
\hline Less than 12 months & $25(24.3)$ \\
\hline 1-2 years & $17(16.5)$ \\
\hline 3-5 years & $18(17.5)$ \\
\hline More than 5 years & $12(11.7)$ \\
\hline I have never been to a dentist & $30(29.1)$ \\
\hline Missing & $1(1.0)$ \\
\hline \multicolumn{2}{|l|}{ What was the reason for your last visit to the dentist? } \\
\hline Consultation/advice & $5(4.9)$ \\
\hline Pain or trouble with teeth, gums or mouth & $22(21.4)$ \\
\hline Treatment / follow up treatment & $11(10.7)$ \\
\hline Routine check-up/ treatment & $20(19.4)$ \\
\hline Don't know/don't remember & $15(14.6)$ \\
\hline No previous dental visit & $30(29.1)$ \\
\hline \multicolumn{2}{|l|}{ Why did you not visit the dentist more frequently? ( $\mathrm{n}=78$, select all that apply) } \\
\hline I do not know where to go to receive dental services & $15(19.2)$ \\
\hline I cannot afford to go to the dentist. & $28(35.9)$ \\
\hline It is hard to find a dentist that accepts my dental plan/Medicaid. & $12(15.4)$ \\
\hline Many services are not covered by my dental plan or Medicaid, so I wind up having to pay out of my own pocket & $25(32.1)$ \\
\hline I am afraid of going to the dentist & $1(1.3)$ \\
\hline Other & $8(10.3)$ \\
\hline No reason & $5(6.4)$ \\
\hline
\end{tabular}

\section{Oral Health Status, Knowledge and Attitude}

Oral health status, knowledge, and attitudes were measured using the indices developed by the ADA Health Policy Institute [19]. To evaluate self-perceived health status, respondents reported how frequently they experienced 11 oral health issues or symptoms. The responses from these 11 questions were then used to create a scale from 0 to 10 , where 0 indicates poor health and 10 indicates the best health. The mean health status score was $7.5(\mathrm{SD}=2.6)$.

To measure oral health knowledge, respondents were asked six true/false questions regarding oral health. The HPI recommends reporting the number responding correctly to all questions. In this sample, $16.9 \%$ answered all oral health questions correctly. The measure for oral health attitude was generated from the respondents' level of agreement with five statements regarding oral health, tooth loss, appearance, and dental visits. The scale reports score from -10 to 10, where higher scores indicate a more positive attitude toward oral health. This sample reported a mean attitude sore of $5.7(\mathrm{SD}=2.1)$. 


\section{Clinical exam findings}

Clinical findings revealed pervasive oral health concerns and treatment needs. On average, participants had 6 decayed teeth, 3.7 missing teeth, and 1.4 filled teeth. As a result, the overall average DMFT score was 11.1 (SD=7.5, Table 4). Additionally, 86\% of participants had a least one site of untreated decay. Participants were also found to have significant periodontal disease. Half were found to have shallow pockets (4-5mm), while 32\% had deep pockets $(6 \mathrm{~mm}$ or more, Table 4$)$. All participants were evaluated to need treatment. Approximately 36\% required "prompt" treatment, while $43.7 \%$ were evaluated to require "urgent" treatment due to pain or infection (Table 4).

Table 4: Oral Health Status-Clinical Findings.

\begin{tabular}{|c|c|}
\hline DMFT & Mean (SD) \\
\hline Decayed & $6.0(5.7)$ \\
\hline Missing & $3.7(4.3)$ \\
\hline Filled & $1.4(3.2)$ \\
\hline Total DMFT Score & $11.1(7.5)$ \\
\hline Community Periodontal Index & $\mathrm{N}(\%)$ \\
\hline Score 0: health periodontal conditions/TN0 & $14(14.9)$ \\
\hline Score 1: gingival bleedings/TN1 & $4(4.0)$ \\
\hline Score 2: shallow periodontal pockets ( 4 to $5 \mathrm{~mm}$ )/TN2 & $51(50.5)$ \\
\hline Score 3: deep periodontal pockets ( $6 \mathrm{~mm}$ or more)/TN3 & $32(31.7)$ \\
\hline Intervention Urgency & $\mathrm{N}(\%)$ \\
\hline No treatment needed & - \\
\hline Preventive or routine treatment needed & $18(17.5)$ \\
\hline Prompt treatment needed & $37(35.9)$ \\
\hline Immediate (urgent) treatment needed due to pain or infection & $45(43.7)$ \\
\hline Referred for comprehensive evaluation (systemic condition) & $2(1.9)$ \\
\hline Missing & $1(1.0)$ \\
\hline
\end{tabular}

\section{Discussion}

When considered together, the DMFT, CPITN, and general evaluation of treatment needs paint a clear picture of the pervasive need for oral health care in this population. All were evaluated to require some form of treatment. The refugees included in this study had a particularly high number of untreated decayed teeth, a high number of extracted teeth, with relatively low numbers of filled teeth. This finding is consistent with other studies that have found that refugees access care later in the disease progression, leading to less restorative care and more urgent treatment, extractions in particular [11, 12, 20, 21]. Participants in this study also reported low utilization of dental care, due primarily to difficulties affording care or finding a provider that accepts Medicaid. The prevalence of decay and disease, coupled with the barriers to accessing care suggests that providing appropriate oral health treatment should be an important priority for resettlement organizations, even beyond the initial three-month period.

This study also highlights the role of education in the oral health of this population. The relatively low percentage of participants who were able to answer all oral health knowledge questions correctly (16.9\%, compared with $56 \%$ of the general Utah population) suggests a need for oral health education [22]. This finding is consistent with other recent studies that have identified important gaps in knowledge regarding oral health among resettled refugees
$[23,24]$. This suggests that refugee populations may benefit from education on appropriate dental hygiene, as well as the early signs and symptoms of oral disease and decay.

The finding of poor knowledge should also be considered in the context of the relatively positive self-reported oral health status. It is also important to note that the relatively positive self-reported oral health status did not correspond with an equally positive clinical exam. As mentioned, this study identified extensive disease, with every participant found to be in need of treatment. The discrepancy between the participants' moderately high levels of self-reported oral health and the poor clinical exam findings could also suggest a lack of education regarding what constitutes good oral health among this refugee population.

Alternatively, the discrepancy between the self-reported oral health status and the findings of the clinical exam may stem less from lack of knowledge and instead from cultural differences in the perception of oral health. One recent systematic review of the role of cultural beliefs related to oral health found that existing research has not done enough to explore and account for cultural beliefs when evaluating oral health status [25]. For example, one study identified extraction of anterior teeth to be a common cultural practice among some Sudanese communities living in the United States [26]. 
Another study of Afghani refugees found that oral health was not a high priority simply because basic safety and survival were the primary focus [27]. These examples of how cultural beliefs could drive one's perception of one's oral health status and treatment needs are part of a small, but growing body of literature. In the case of this study, the discrepancy between self-reported oral health status and the clinical exam could be indicative of expectations and desires for oral health among refugee populations that differ from current Western-derived ideals. While this study does highlight education as a powerful avenue for improving the oral health status of refugees living in Utah, any educational programs would first need to evaluate the cultural perceptions of the targeted learners and design any educational program in a manner that respects the cultural differences, while also achieving reductions in oral disease and decay.

\section{Limitations}

Limitations of this study include the use of convenience sampling and potential self-selection bias. This pilot study is limited in its generalizability due to the sample size and the geographic concentration of study participants. Findings, therefore, cannot be extrapolated to other refugees nationally or globally. Additionally, because information on the length of time in the United States was not collected, the impact of the initial three-month period of treatment or, conversely, prolonged time in the United States could not be evaluated. It is quite possible that time in the United States significantly impacts oral health knowledge and treatment needs, resulting in education and treatment approaches that may vary significantly within the refugee population.

\section{Conclusion}

This study provided evidence of the extent of oral disease and decay among refugees resettled in the Salt Lake City area. Participants were found to have high levels of active decay, as well as extensive periodontal disease. Because of the pervasiveness of treatment needs, refugees would benefit from additional support from resettlement and public health agencies in accessing oral health care, particularly beyond the initial resettlement period. This study also identified low levels of oral health knowledge. A targeted, culturally appropriate program to educate refugees on oral hygiene and the early signs and symptoms of oral disease could provide this refugee population with some of the tools they need to improve their oral health.

\section{Knowledge Transfer Statement}

This study will allow us to develop future culturally appropriate programs to educate refugees on oral hygiene, signs and symptoms of oral disease to improve their oral health.

\section{Acknowledgment}

This project was supported by University of Utah Health Studies Fund (PI: Lilliam Pinzon). The findings of this study was presented at IADR/AADR/CADR 2019 conference.

\section{Declaration of Conflicting Interest}

The Authors declare that there is no conflict of interests. All manuscript's copyright ownership is transferred from the author(s) of the article to the JDR Clinical \& Translational Research in the event the work is published. The manuscript has not been published in any form or any language and is only submitted to the JDR Clinical \& Translational Research.

\section{References}

1. Weis P (Edt.) (1995) The refugee convention (1951) 7: 533-558, Research Centre for International Law University of Cambridge. New York: Cambridge University Press, USA.

2. Cote S, Geltman P, Nunn M, Lituri K, Henshaw M, Garcia RI (2004) Dental caries of refugee children compared with US children. Pediatrics 114(6): e733-740.

3. Ogunbodede EO, Mickenautsch S, Rudolph MJ (2000) Oral Health Care in Refugee Situations: Liberian Refugees in Ghana. J Refug Stud 13(3): 328-335.

4. Smith DK, Szuster F (2000) Aspects of tooth decay in recently arrived refugees. Aust N Z J Public Health 24(6): 623-626.

5. Gift HC (1984) Utilization of professional dental services. In: Cohen LK, Bryant PS (Eds,). Social Sciences and Dentistry: A Critical Bibliography. Volume 2, London: Quintessence Publishing Company Ltd, Pp: 202-267.

6. National Institute of Dental and Craniofacial Research, National Institute of Health, U.S. Public Health Service, Department of Health and Human Services (2005) The invisible barrier: literacy and its relationship with oral health. A report of a workgroup sponsored by the National Institute of Dental and Craniofacial Research, National Institute of Health, U.S. Public Health Service, Department of Health and Human Services. J Public Health Dent 65(3):174-182.

7. Telford C, Coulter I, Murray L (2011) Exploring socioeconomic disparities in self-reported oral health among adolescents in California. J Am Dent Assoc 142(1): 70-78.

8. Nainar SM, Tinanoff N (1997) Effect of Medicaid reimbursement rates on children's access to dental care. Pediatr Dent 19(5): 315-316.

9. Graham MA, Tomar SL, Logan HL (2005) Perceived social status, language and identified dental home among Hispanics in Florida. J Am Dent Assoc 136(11):1572-1582.

10. Patrick DL, Lee RSY, Nucci M, Grembowski D, Jolles CZ, et al. (2006) Reducing Oral Health Disparities: A Focus on Social and Cultural Determinants. BMC Oral Health. 6 Suppl 1(Suppl 1): S4.

11. Singh HK, Scott TE, Henshaw MM, Cote SE, Grodin MA, et al. (2008) Oral health status of refugee torture survivors seeking care in the United States. Am J Public Health 98(12): 2181-2182.

12. Ghiabi E, Matthews DC, Brillant MS (2014) The oral health status of recent immigrants and refugees in Nova Scotia, Canada. J Immigr Minor Health 16(1): 95-101.

13. Chong JW (2015) Mental Health on Arrival: An Analysis of Refugee Mental Health in Utah. Utah Department of Health.

14. Bureau of Epidemiology, Utah Department of Health. Refugee health statistics for arrivals to Utah: 2015 Refugee statistics.

15. Workforce Services Refugee Services. Refugee center: Programming.

16. Steed S, Rabin M, Oral Health of Utah Refugees. Utah Department of Health.

17. Utah Department of Health. Refugee Health Program.

18. Cutress TW, Ainamo J, Sardo Infirri J (1987) The community periodontal index of treatment needs (CPITN) procedure for population groups and individuals. Int Dent J 37(4): 222-233. 
19. Yarbrough C, Starkel R, Vujicic M, Aravamudhan K, Meyer DM (2015) Methodology for Developing the Health Policy Institute Index Measures of Oral Health Status, Oral Health Knowledge, and Attitude Toward Oral Health. Health Policy Institute. American Dental Association.

20. Davidson N, Skull S, Calache H, Murray SS, Chalmers J (2006) Holes a plenty: oral health status a major issue for newly arrived refugees in Australia. Aust Dent J 51(4): 306-311.

21. Keboa MT, Hiles N, Macdonald ME (2016) The oral health of refugees and asylum seekers: a scoping review. Global Health 12(1): 59.

22. Health Policy Institute (2015), American Dental Association. Utah's Oral Health and Well-Being.

23. Prowse S, Schroth RJ, Wilson A, Edwards JM, Sarson J, et al. (2014) Diversity Considerations for Promoting Early Childhood Oral Health: A Pilot Study. Int J Dent 175084.
24. Riggs E, Gibbs L, Kilpatrick N, Gussy M, van Gemert C, et al. (2015) Breaking down the barriers: a qualitative study to understand child oral health in refugee and migrant communities in Australia. Ethn Health 20(3): 241-257.

25. Butani Y, Weintraub JA, Barker JC (2008) Oral health-related cultural beliefs for four racial/ethnic groups: Assessment of the literature. BMC Oral Health 8:26.

26. Willis MS, Schacht RN, Toothaker R (2005) Anterior dental extractions among Dinka and Nuer refugees in the United States: a case series. Spec Care Dentist 25(4): 193-198.

27. Lamb CEF, Michaels C, Whelan AK (2009) Refugees and oral health: lessons learned from stories of Hazara refugees. Aust Health Review 33(4): 618-627. 